\title{
Diseño tecnológico del procesamiento de salchichas de alpaca de alto contenido proteico
}

Norma Salas De La Torre* Rosa Laura Lengua Calle** BECERra VÁSQuez***

\begin{abstract}
RESUMEN
La finalidad de esta investigación es revalorar carnes no tradicionales, que en forma de embutidos lograrán ingresar al mercado en función a sus cualidades nutricionales, como es el bajo nivel de colesterol y alto contenido de proteínas que ostenta la carne de alpaca frente a la carne de cerdo, igualmente revalorar la carne de oveja. La presencia de Gigartina chamissoi (yuyo) en la formulación es importante por ser fuente de iodo, polisacáridos complejos (fibra) y gelificantes naturales que elevan su valor biológico. Gigartina chamissoi, aparte de elevar su valor nutritivo, se constituye en un producto prebiótico por contrarrestar propensiones a la generación de células cancerígenas que se presentan en tejidos como mucosas (esófago, estómago), glandulares (mamario) y glandular-vesicular (próstata). Para el efecto se ha elaborado un diseño experimental que permita fabricar embutidos en condiciones higiénicas sanitarias óptimas. El análisis químico proximal del producto terminado (Tabla $\mathrm{N}^{0} \mathrm{9}$ ), demostró que la Formulación S-2, arroja un alto contenido proteico y bajo nivel de grasa. El nivel proteico del producto La Segoviana (por porción de 35 gramos) es 3,39 g y la Formulación S-2 (por porción de 35 gramos) es de $5,23 \mathrm{~g}$. La evaluación sensorial que se efectuó mediante el Test Escala Hedónica (Tabla № 11) arrojó resultados óptimos en cuanto a textura y sabor frente a las marcas San Fernando y La Segoviana.
\end{abstract}

Palabras clave: inactivación enzimática, revalorar carnes, polímeros naturales, prebiótico, alto valor biológico.

Technological design alpaCa SaUSAge processing high PROTEIN CONTENT

\section{ABSTRACT}

The current research aims to reassess no traditional meats that in sausage shape get to entry in the local market, according to their nutritional qualities, such as low cholesterol and high protein, which shows the alpaca meat against pork, and also revalue mutton. The presence of Gigartina chamissoi (seaweed) in the formulation is important as a source of iodine, complex polysaccharides (fiber) and natural gelling agents which increase its biological value. Gigartina chamissoi besides raise its nutritional value, constitutes a prebiotic product for counter propensities against cancer cells in tissues such as mucous (esophagus, stomach), glandular (breast) and glandularvessels (prostate). To this effect has been developed an experimental design allowing manufacture sausages in more optimal hygienic conditions. The proximal chemical analysis of the finished product (Table 9) showed that Formulation S-2, resulting in a high protein and low fat. The protein level of Segoviana product (per 35 grams portion) is $3.39 \mathrm{~g}$, and the Formulation S-2 (per 35 grams portion) is 5.23 g. The sensory evaluation was performed using the Hedonic Scale Test (Table 11) yielded optimal results in terms of texture and flavor compared to San Fernando and Segovia brands.

Keywords: enzyme inactivation, reassess meats, natural polymers, prebiotic, high biological value

\section{INTRODUCCIÓN}

La producción de las carnes tradicionales de mayor consumo no es suficiente para cubrir la demanda nacional, tanto así que importamos carnes de aves, res y cerdo, entre otros, generando un dilema del porqué no se valora el consumo de carne de alpaca que alimentó al poblador andino, siendo además ésta una gran fuente de proteínas y con un contenido muy bajo de colesterol, tan perjudicial para nuestro organismo ${ }^{1}$.

Por otra parte las algas y sus derivados forman parte de nuestra vida cotidiana en forma de alimentos, fármacos, cosméticos, etc.

Recientes investigaciones sustentan que, además de los oligoelementos, proteínas y vitaminas, los polisacáridos, que son complejos obtenidos de las algas, especialmente los carragenanos, tendrían una acción inhibidora de ciertos virus, razón por la que estas algas marinas son consideradas como alimento nutraceútico ${ }^{2}$.

El diseño experimental implica obtener un producto de consumo alimenticio de alto contenido proteico, lo cual se debe conseguir fusionando las carnes de alpaca, la de la oveja y el yuyo en la producción de embutidos.

La carne de alpaca tiene un contenido de $101 \mathrm{kcal} / 100 \mathrm{~g}$ de pulpa (Instituto Nacional de Nutrición 1993), 22,10\% de proteína, $6,20 \%$ de grasa, $4,00 \%$ de cenizas (Ponce, 1971), mientras que la carne de cerdo, muy consumido por nuestra población, contiene $275 \mathrm{Kcal} / 100 \mathrm{~g}$ de pulpa (Instituto Nacional de Nutrición 1993), 19,37\% de proteína, 20,6\% de grasa, 0,79\% de cenizas (Ponce, 1971) 5 .

Por consiguiente, observamos que la carne de alpaca, respecto a las otras mencionadas, es la que contiene menor porcentaje de calorías, haciéndola más saludable.

No se han reportado trabajos que científicamente, puedan demostrar

\footnotetext{
* Ingeniero Químico. Departamento de Procesos de Facultad de Química e Ingeniería Química-UNMSM. E-mail: nsalasd@hotmail.com

** Química. Departamento de Química Analítica e Instrumentación. Facultad de Química e Ingeniería Química-UNMSM. E-mail: 1qac1@hotmail.com

*** Química. Departamento de Química Analítica e Instrumentación. Facultad de Química e Ingeniería Química-UNMSM. E-mail: ebecerrav@hotmail.com
} 
Los beneficios de éstos en la alimentación, por lo que no se tomaron como referencia.

\section{METODOLOGÍA DEL TRABAJO}

Para el procesamiento de las salchichas a elaborar, finalidad de este estudio, con un alto valor proteico en base a la fusión de la carne de alpaca, la carne de oveja y de la Macroalga yuyo, se ensayaron diferentes formulaciones, siendo las más representativas y las que se han tomado en cuenta en este trabajo, las dos siguientes series de formulaciones, nominadas como: Serie 2 (S-2) y Serie $5\left(\right.$ S-5), las que fueron evaluadas ${ }^{6}$.

\subsection{Materiales}

\section{Materia prima}

Carne de alpaca, carne de oveja, Macroalga Gigartina chamissoi.

\section{Insumos}

Hielo, chuño, sal común, sal de Praga, polifosfato de potasio, lactato de sodio, condimento salchicha, pimienta molida, comino, ajo y cebolla en polvo, tripa de celulosa transparente calibre $24 \mathrm{~mm}$ de diámetro.

\section{Equipos}

Las experiencias de laboratorio se efectuaron en las instalaciones de la Escuela Académico Profesional de Ingeniería Agroindustrial de la Facultad de Química e Ingeniería Química de la Universidad Nacional Mayor de San Marcos, empleando los equipos que a continuación se detallan:Cutter CU 324 (capacidad de $14 \mathrm{~kg}$ ), molino para carne Skymsen PSEE-22HD (capacidad de $10 \mathrm{~kg}$ ), embutidora Tre Spade 21100/L (capacidad 10 $\mathrm{kg}$ ), cocina a gas Miray Princesa 4 hornillas, balanza Mitchel FD 15 (capacidad $10 \mathrm{~kg}$ ), Balanza electrónica Mitchel (capacidad $35 \mathrm{~kg}$ ), refrigeradora Coldex no frost RN36.

\subsection{Métodos}

Para el procesado de embutidos debemos contar con materiales y equipos completamente limpios evitando introducir gérmenes por contaminaciones secundarias. La mayoría de los embutidos contienen sustancias curantes que resalten el sabor, aroma y color característico de carne curada, además de eliminar cualquier microorganismo contaminante ${ }^{6,8}$.

\section{Picado}

El picado se efectúa en el cutter agregando carne congelada, grasa congelada, hielo, sales curantes, especias y aditivos hasta tamaño de grano deseado.

\section{Embutido}

Es la operación de embutir la masa cárnica, debe quedar firme y compacta sin espacios en el producto final. En la experiencia se ha utilizado tripa de celulosa calibre 24 .

\section{Escaldado}

Se efectúa a $80^{\circ} \mathrm{C}$ (en marmita) cuidando que la temperatura desde el inicio al final se mantenga constante por 35 minutos.

\section{Enfriado}

Las salchichas deben ser enfriadas con agua fría, inclusive la parte interna de ella, seguidamente debe alcanzar $28^{\circ} \mathrm{C}$, seguidamente debe permanecer 24 horas en cámara de frío a $4^{\circ} \mathrm{C}$ para que la proteína de la carne ligue el exceso de humedad y desarrollen sus propiedades sensoriales (sabor y aroma).

\section{PARTE EXPERIMENTAL}

\section{a. Preparación de la Materia Prima}

Las carnes de alpaca y de oveja, son de procedencia de las alturas del Departamento de Junín, las algas marinas son de procedencia de la Bahía de Paracas, la manteca vegetal y las especies fueron adquirida en el mercado de Surquillo, previamente se analizaron sensorialmente para reconocer la frescura de todos estos insumos. Las carnes y grasa se empacaron en bolsas separadas, al igual que las algas y se colocaron en la congeladora (refrigeradora Coldex no frost RN 36, de la EAP de Ingeniería Agroindustrial), luego de enfriarlos se procedió a cortarlos en trozos de tamaño de $3 \times 3 \mathrm{~cm}$, a fin de facilitar el picado posterior. Una vez trozado se pesaron por separado en una balanza electrónica (balanza electrónica Mitchel FD 35 , capacidad de $35 \mathrm{~kg}$, de la EAP de Ingeniería Agroindustrial) de acuerdo a las formulaciones empleadas, del mismo modo las especias, hielo, sales, conservador y colorantes ${ }^{10}$.

\section{b. Formulación del Pastón Base}

Finalizado el pesado, se procedió a colocarlo en el Cutter (CU 314 capacidad de $14 \mathrm{~kg}$, de la EAP de Ingeniería Agroindustrial) para su picado, iniciándose con las diferentes carnes, luego se agregó el hielo, cuya finalidad es el de bajar la temperatura del picado luego se adiciona la sal. Posteriormente se agregó las especias, las algas, grasa y nuevamente el hielo; se procedió al picado fino hasta obtener un pastón fino de color rojo claro, finalmente se agregó el chuño para obtener una textura estable ${ }^{6,10}$. 


\section{c. Elaboración del Embutido}

Elaborado el pastón base, se procedió a colocarlo en una embutidora (Tre Spade 21100 capacidad de $10 \mathrm{~kg}$, de la EAP de Ingeniería Agroindustrial), a fin de embutir la pasta en forma de una tripa sintética (de calibre $24 \mathrm{~mm}$ de diámetro) y luego fue porcionado a un tamaño de $12 \mathrm{~cm}$ de largo ${ }^{10}$.

\section{d. Escaldado}

Una vez realizado el porcionado, las salchichas formadas se colocaron en una marmita para escaldarlo a una temperatura de $80^{\circ} \mathrm{C}$ por 35 minutos; finalmente fueron enfriados y refrigerados $2-4^{\circ} \mathrm{C}$, lo que se observa en el diagrama de flujo siguiente ${ }^{6,10}$.

\section{Diagrama de Flujo del Procesamiento de Salchichas}

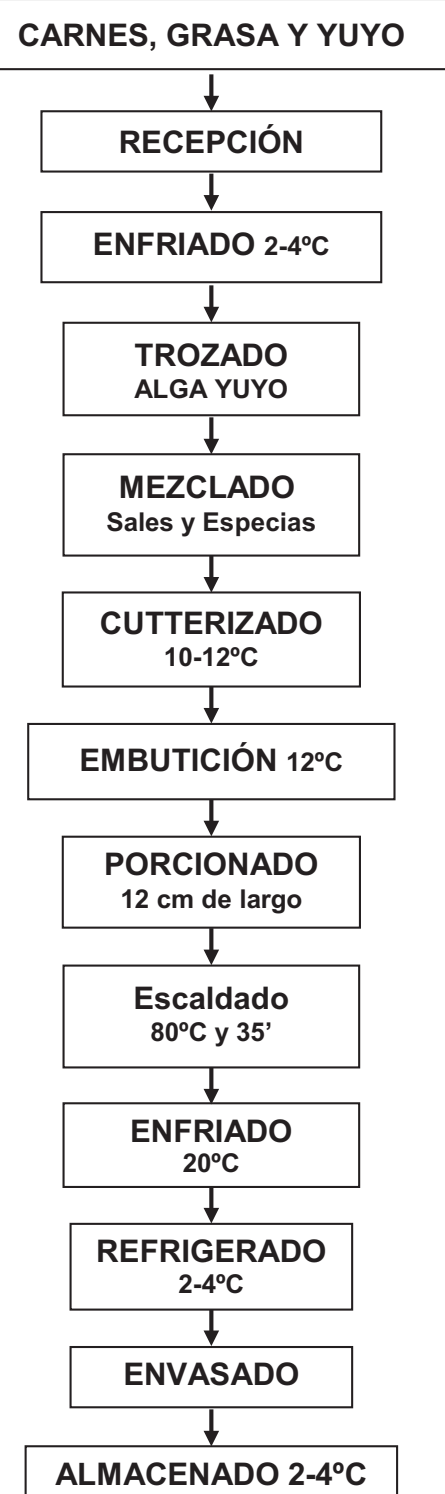

\section{COMPOSICIÓN QUÍMICA Y VALOR NUTRI- CIONAL}

Composición química en minerales, vitaminas y aminoácidos de la harina de alga (Gigartina chamissoi).

Tabla 1. Minerales

\begin{tabular}{|c|c|c|}
\hline \multirow{2}{*}{ MINERAL } & \multicolumn{2}{|c|}{ CONTENIDO } \\
\cline { 2 - 3 } & $\%$ & $\mathbf{p p m}$ \\
\hline Yodo & 7,21 & \\
\hline Calcio & 6,41 & \\
\hline Magnesio & 12,69 & \\
\hline Cloruro de sodio & 3,46 & \\
\hline Niquel & & 0,09 \\
\hline Silicio & & 0,30 \\
\hline Fosforo & 0,35 & \\
\hline Hierro & & 1,10 \\
\hline
\end{tabular}

Fuente: Laboratorios de la Facultad de Farmacia y Bioquímica de la UNMSM.

Tabla 2. Vitaminas

\begin{tabular}{|c|c|}
\hline VITAMINAS & $\begin{array}{c}\text { CONTENIDO } \\
\text { mg/100 g muestra }\end{array}$ \\
\hline Ácido Ascórbico & 128,9 \\
\hline Piridoxina & 2,32 \\
\hline Tiamina & 0,10 \\
\hline Riboflavina & 0,170 \\
\hline Carotenos & $5 \times 10-4$ \\
\hline
\end{tabular}

Fuente: Laboratorios de Facultad de Farmacia y Bioquímica de la UNMSM.

Tabla 3. Aminoácidos

\begin{tabular}{|c|c|}
\hline AMINOÀCIDOS & $\begin{array}{c}\text { CONTENIDO } \\
\text { g/100g proteína }\end{array}$ \\
\hline Arginina & 18,7 \\
\hline Lisina & 2,9 \\
\hline Triptofano & 1,2 \\
\hline Metionina & 0,8 \\
\hline Cistina & 0,4 \\
\hline Treonina & 2,3 \\
\hline
\end{tabular}

Fuente: Laboratorios de Facultad de Farmacia y Bioquímica de la UNMSM 
Tabla 4. Comparación de la composición química de la carne de alpaca y otros animales de abastecimiento, \%.

\begin{tabular}{|c|c|c|c|c|c|}
\hline CARNE & HUMEDAD $\%$ & PROTEÍNA $\%$ & GRASA $\%$ & CENIZA $\%$ & CARBOHIDRATO $\%$ \\
\hline Alpaca & 65,70 & 22,10 & 6,20 & 4,00 & 2,00 \\
\hline Llama & 69,17 & 24,82 & 3,69 & 1,41 & 0,91 \\
\hline Ovino & 72,21 & 18,91 & 6,53 & 2,16 & 0,16 \\
\hline Cabra & 73,80 & 20,65 & 4,30 & 1,25 & - \\
\hline Porcino & 59,18 & 19,37 & 20,06 & 0,79 & 0,60 \\
\hline Vacuno & 72,01 & 21,01 & 4,84 & 0,90 & 1,23 \\
\hline
\end{tabular}

Fuente: Ponce. UNALM (1971)

\section{RESULTADOS}

Tabla 5. Análisis Cualitativo de la Gigartina chamissoi (Yuyo)

\begin{tabular}{|c|c|c|}
\hline PARÁMETRO & CONTENIDO & PROPORCIÒN \\
\hline Humedad & $6,06 \%$ & \\
\hline Cenizas & $67,33 \%$ & +++ \\
\hline Calcio & Positivo intermedio & ++++ \\
\hline Magnesio & Mayor (positivo) & ++++ \\
\hline Zinc & Mayor (positivo) & + \\
\hline PO4-3 & Positivo (intermedio) & + \\
\hline Hierro & Poco & + \\
\hline Potasio & Poco & + \\
\hline Manganeso & Poco & \\
\hline
\end{tabular}

Fuente: Elaborado por Miembro del Proyecto: Química Becerra Vásquez, Elvira.

Tabla 6. formulaciones serie 2 (S-2) y Serie 5 (S-5) (Base: 2 kg de producto)

\begin{tabular}{|c|c|c|}
\hline INGREDIENTES & S-2 $(\mathbf{g})$ & S-5 (g) \\
\hline Carne de alpaca & 900 & 700 \\
\hline Carne de oveja & 400 & 500 \\
\hline Grasa & 280 & 284 \\
\hline Hielo & 400 & 500 \\
\hline Alga & 20 & 16 \\
\hline
\end{tabular}

Fuente: Elaboración de la Responsable del Proyecto.
Tabla 7. Determinación de PH de las carnes procesadas

\begin{tabular}{|c|c|c|}
\hline & Carne alpaca & Carne oveja \\
\hline $\mathbf{p H}$ & 5,7 & 5,8 \\
\hline
\end{tabular}

Fuente: Laboratorio de Investigación y Desarrollo de la EAP de Ingeniería Agroindustrial.

Tabla 8. Rendimiento en la producción de salchichas procesadas

\begin{tabular}{|c|c|c|c|}
\hline Formulación & $\begin{array}{c}\text { Materia } \\
\text { prima (kg) }\end{array}$ & $\begin{array}{c}\text { Producto } \\
\text { final (kg) }\end{array}$ & $\begin{array}{c}\text { Rendimiento } \\
\mathbf{( \% )}\end{array}$ \\
\hline S-2 & 2,08 & 1,55 & 75 \\
\hline S-5 & 2,09 & 1,72 & 82 \\
\hline
\end{tabular}


Tabla 9. Análisis químico proximal mediante sistema GEHA de la formulación S-2. Considerando peso de muestra y su contenido porcentual indicado en Tabla $N^{\circ} 4$

\begin{tabular}{|c|c|c|c|c|c|c|c|c|c|c|c|}
\hline \multirow{2}{*}{ S-2 } & \multirow{2}{*}{$\mathbf{k g}$} & \multicolumn{2}{|c|}{ Agua } & \multicolumn{2}{c|}{ Grasa } & \multicolumn{2}{c|}{ Proteinas } & \multicolumn{2}{c|}{ Carbohidratos } & \multicolumn{2}{c|}{ Ceniza } \\
\cline { 3 - 12 } & & $\%$ & $\mathbf{k g}$ & $\%$ & $\mathbf{k g}$ & $\mathbf{\%}$ & $\mathbf{k g}$ & $\%$ & $\mathbf{k g}$ & $\%$ & $\mathbf{k g}$ \\
\hline Alpaca & 45 & 65,70 & 29,57 & 6,20 & 2,79 & 22,10 & 9,95 & 2,00 & 0,9 & 4,00 & 1,8 \\
\hline Ovino & 20 & 72,21 & 14,44 & 6,53 & 1,31 & 18,91 & 3,78 & 0,16 & 3,2 & 2,19 & 0,43 \\
\hline Grasa & 14 & 18,94 & 2,65 & 77,4 & 10,84 & 3,64 & 0,51 & - & - & 0,02 & - \\
\hline Hielo & 20 & 100 & 20,00 & - & - & - & - & - & - & - & \\
\hline Yuyo & 1 & 14,22 & 0,14 & 0,18 & - & 16,38 & 0,163 & 52.61 & 0.53 & 16,61 & 0,17 \\
\hline$\%$ Total & 100 & & 66,80 & & 14,94 & & 14,40 & & 4,63 & & 2,4 \\
\hline
\end{tabular}

Fuente: Elaboración de la Responsable del Proyecto Ing. N. Salas y J. Pareja

Tabla 10. Análisis químico proximal mediante sistema GEHA de la formulación S-5

\begin{tabular}{|c|c|c|c|c|c|c|c|c|c|c|c|}
\hline \multirow{2}{*}{ S-5 } & \multirow{2}{*}{$\mathbf{k g}$} & \multicolumn{2}{|c|}{ Agua } & \multicolumn{2}{c|}{ Grasa } & \multicolumn{2}{c|}{ Proteinas } & \multicolumn{2}{c|}{ Carbohidratos } & \multicolumn{2}{c|}{ Ceniza } \\
\cline { 3 - 13 } & & $\%$ & $\mathbf{k g}$ & $\%$ & $\mathbf{k g}$ & $\%$ & $\mathbf{k g}$ & $\%$ & $\mathbf{k g}$ & $\%$ & $\mathbf{k g}$ \\
\hline Alpaca & 35 & 65,70 & 23,00 & 6,20 & 2,17 & 22,10 & 7,74 & 2,00 & 0,7 & 4,00 & 1,4 \\
\hline Ovino & 25 & 72,21 & 18,05 & 6,53 & 1,63 & 18,91 & 4,73 & 0,16 & 0,04 & 2,19 & 0,55 \\
\hline Grasa & 14,2 & 18,94 & 2,69 & 77,4 & 10,99 & 3,64 & 0,52 & - & - & 0,02 & - \\
\hline Hielo & 25 & 100 & 25 & - & - & - & - & - & - & - & - \\
\hline Yuyo & 0,8 & 14,22 & 0,1137 & 0,18 & 0,18 & 16,38 & 0,13 & 52,61 & 0,42 & 16,61 & 0,13 \\
\hline$\%$ Total & 100 & & 68,85 & & 14,97 & & 13,12 & & 1,16 & & 2,08 \\
\hline
\end{tabular}

Fuente: Elaboración de la Responsable del Proyecto Ing. N. Salas y J. Pareja

ESCALA HEDÓNICA PARA LA EVALUACIÓN SENSORIAL DE LA SALCHICHA FORMULADA

\begin{tabular}{|c|c|}
\hline ESCALA & EVALUACIÓN \\
\hline 10 & ME GUSTA MUCHÍSIMO \\
\hline 6 & ME GUSTA MUCHO \\
\hline 4 & ME GUSTA \\
\hline 2 & ME GUSTA POCO \\
\hline 0 & ME ES INDIFERENTE \\
\hline-2 & NO ME GUSTA \\
\hline-4 & ME DISGUSTA POCO \\
\hline-6 & ME DISGUSTA \\
\hline-10 & ME DISGUSTA MUCHÍSIMO \\
\hline
\end{tabular}


Tabla 11. resultado de la escala hedónica de la formulación s-2

\begin{tabular}{|c|c|c|c|}
\hline Muestra & $\begin{array}{c}\text { A } \\
(\mathbf{S}-2)\end{array}$ & $\begin{array}{c}\text { B } \\
\text { (La Segoviana) }\end{array}$ & $\begin{array}{c}\text { C } \\
\text { (San Fernando) }\end{array}$ \\
\hline S-2 & 10 & 7,5 & 10 \\
\hline
\end{tabular}

Tipo de salchicha a evaluar: Hot dog

Analizando los resultados observamos que existe diferencia significativa entre las muestras A (Formulación S-2) y B (La Segoviana).

No existe diferencia significativa entre las muestras A (Formulación S-2) y C (San Fernando).

\section{DISCUSIÓN DE RESULTADOS}

Los valores de $\mathrm{pH}$ de la carne de alpaca y oveja utilizadas se enmarcan dentro del rango permitido por la norma técnica peruana $(\mathrm{pH} 5,5-6,4)$.

El contenido de proteína en el producto La Segoviana en una porción de 35 gramos arroja 3,39 $\mathrm{g}$ de proteína y la formulación $\mathrm{S}-2$ (por porción de 35 gramos) arroja 5,23g de proteína, que rebasa ampliamente a la marca comercial de referencia.

La formulación seleccionada fue S-2, por presentar valores más altos en cuanto a proteínas, carbohidratos y cenizas respecto de la formulación S-5. (Tabla N9 y 10)

Se aplicó la prueba de evaluación sensorial Scoring y Escala Hedónica, con 6 panelistas.

Al comparar las muestras A (Formulación S-2) y B (La Segoviana) se aprecia una mayor aceptación hacia el producto $A$, tal como se observa en la TABLA N¹1.

La textura de la salchicha es calificada como muy buena por los panelistas, destacando su sabor y buen corte, observándose además un alto porcentaje de carne de alpaca $(45 \%)$ y oveja $(20 \%)$ elevando el valor proteico del producto.

El agregado de Gigartina chamissoi en la formulación S-2 se observa que enriquece el producto terminado por el alto contenido de Calcio, Fósforo, Hierro, Magnesio y otros elementos que presenta la macroalga (Tabla $N^{\circ} 5$ ).

\section{CONCLUSIONES}

- Sobre la base conceptual del diseño de procesos se crea las formulaciones S-2 y S-5 además del diagrama de flujo soportado en el sistema
GEHA, empleando carne de alpaca (40\%), oveja $(20 \%)$ y yuyo, tal como se observa en la Tabla $N^{\circ} 6$.

- El análisis químico proximal del producto terminado S-2, arroja un alto contenido proteico y bajo nivel de grasa (Tabla $N^{\circ} 9$ ), y niveles de colesterol muy bajo en comparación con las salchichas de las marcas comerciales analizadas, que sumadas a sus propiedades sensoriales logramos obtener embutidos sabrosos y altamente nutritivos que se enmarcan dentro de los alimentos funcionales por sus propiedades de reducción del riesgo cardiovascular y obesidad.

- El producto elaborado Formulación S-2, ostenta el mayor contenido de proteínas respecto a las salchichas de las marcas comerciales San Fernando y La Segoviana.

- La evaluación sensorial que se efectuó a los productos de las formulaciones S-2 y S-5 mediante el Test Escala Hedónica (Tabla № 11) arrojó resultados óptimos en cuanto a textura y sabor frente a las marcas La Segoviana y San Fernando, que nos garantizan competir en el mercado.

- Revalorar las carnes de alpaca y oveja en la elaboración de embutidos, creando mayor valor agregado, propiciando el desarrollo económico de las zonas altoandinas que son eminentemente alpaqueras.

- Contribuir a la crianza de camélidos andinos, generando fuente de ingresos para las zonas más deprimidas del país.

\section{REFERENCIAS BIBLIOGRÁFICAS}

[1] Acleto O., Zuñiga (1998). Introducción a las algas. Editorial Escuela nueva S. A. Lima, Perú.

[2] Alana E. Vallejos, Aojalla R., Quispe (2003). Estudio del Efecto Lipemiante de Polisacáridos sulfatados de la fase tetraspòrica del alga Chondracanthus Chamissoi en conejos. Tesis 
de la Facultad de Farmacia y Bioquímica. UNMSM, Lima, Perú.

[3] Bello, J. (1993) Temas actuales sobre carnes y derivados Universidad de Navarra. España

[4] Fuertes C., Ruiton. (1998) Polisacáridos sulfatados de algas marinas. Elucidación estructura. Actividad antiviral frente al virus del VIH. Tesis de la facultad de Farmacia y Bioquímica. UNMSM, Lima, Perú.

[5] Instituto Nacional de Nutrición (2010). Composición de alimentos de mayor consumo en el Perú. Ministerio de Salud.

[6] J.Pareja M. (2012). Embutidos, elaboración y recetas.
[7] Paz J., Villalobos (1995). Algas marinas del Perú. Revista académica de la Facultad de Ingeniería Industrial de la Universidad de Lima 75-78.

[8] Stiebing, A. (2007) Embutidos escaldados de mayor conservación. Fleischwirtschaft 44-50. Alemania.

[9] Tabachi P., García. (1999). Estudio de las algas rojas Revista Química.

[10] Wirth, F. (2002) Tecnología de los Embutidos Escaldados. Ed. Acribia. Madrid. España. Ministerio de Salud. Perú

[11] Norma Técnica Peruana 201.012 (1999). Carne y productos cárnicos. Indecopi. 